\title{
Enhancing socially shared regulation in collaborative learning groups: designing for CSCL regulation tools
}

Citation for published version (APA):

Järvelä, S., Kirschner, P. A., Panadero, E., Malmberg, J., Phielix, C., Jaspers, J., Koivuniemi, M., \& Järvenoja, $\mathrm{H}$. (2015). Enhancing socially shared regulation in collaborative learning groups: designing for CSCL regulation tools. Educational Technology Research and Development, 63(1), 125-142. https://doi.org/10.1007/s11423-0149358-1

\section{DOI:}

10.1007/s11423-014-9358-1

Document status and date:

Published: 01/02/2015

Document Version:

Other version

Document license:

CC BY-NC-ND

Please check the document version of this publication:

- A submitted manuscript is the version of the article upon submission and before peer-review. There can be important differences between the submitted version and the official published version of record. People interested in the research are advised to contact the author for the final version of the publication, or visit the DOI to the publisher's website.

- The final author version and the galley proof are versions of the publication after peer review.

- The final published version features the final layout of the paper including the volume, issue and page numbers.

Link to publication

\section{General rights}

Copyright and moral rights for the publications made accessible in the public portal are retained by the authors and/or other copyright owners and it is a condition of accessing publications that users recognise and abide by the legal requirements associated with these rights.

- Users may download and print one copy of any publication from the public portal for the purpose of private study or research.

- You may not further distribute the material or use it for any profit-making activity or commercial gain

- You may freely distribute the URL identifying the publication in the public portal.

If the publication is distributed under the terms of Article 25fa of the Dutch Copyright Act, indicated by the "Taverne" license above, please follow below link for the End User Agreement:

https://www.ou.nl/taverne-agreement

Take down policy

If you believe that this document breaches copyright please contact us at:

pure-support@ou.nl

providing details and we will investigate your claim.

Downloaded from https://research.ou.nl/ on date: 26 Apr. 2023 


\title{
Enhancing socially shared regulation in collaborative learning groups: designing for $\mathrm{CSCL}$ regulation tools
}

\author{
Sanna Järvelä • Paul A. Kirschner • Ernesto Panadero • \\ Jonna Malmberg • Chris Phielix • Jos Jaspers • Marika Koivuniemi • \\ Hanna Järvenoja
}

Published online: 11 October 2014

(C) Association for Educational Communications and Technology 2014

\begin{abstract}
For effective computer supported collaborative learning (CSCL), socially shared regulation of learning (SSRL) is necessary. To this end, this article extends the idea first posited by Järvelä and Hadwin (Educ Psychol 48(1):25-39, 2013) that successful collaboration in CSCL contexts requires targeted support for promoting individual selfregulatory skills and strategies, peer support, facilitation of self-regulatory competence within the group, and SSRL. These (meta)cognitive, social, motivational, and emotional aspects related to being/becoming aware of how one learns alone and with others are for the most part neglected in traditional CSCL support. Based upon a review of theoretical and empirical studies on the potential of and challenges to collaboration, three design principles for supporting SSRL are introduced: (1) increasing learner awareness of their own and others' learning processes, (2) supporting externalization of one's own and others' learning process and helping to share and interact, and (3) prompting acquisition and activation of regulatory processes. Finally, an illustrative example is presented for how these principles are applied in a technological tool for supporting SSRL.
\end{abstract}

Keywords Computer supported collaborative learning - Collaborative learning · Self-regulated learning · Socially shared regulation of learning · Technological tools

\footnotetext{
S. Järvelä $(\bowtie)$ E. Panadero · J. Malmberg · M. Koivuniemi · H. Järvenoja Learning and Educational Technology Research Unit (LET), Department of Educational Sciences and Teacher Education, University of Oulu, P.O. BOX 2000, 90014 Oulu, Finland e-mail: sanna.jarvela@oulu.fi

P. A. Kirschner

Open University of The Netherlands, Heerlen, Netherlands

C. Phielix $\cdot$ J. Jaspers

University of Utrecht, Utrecht, Netherlands
} 


\section{Introduction}

Learning has been moving from a purely individual and externally programmed endeavor (i.e., planned and executed with the aid of a teacher) to learning in and with groups in a problem-based or inquiry-based situation. This is the case not only in the classroom but also in distributed environments (Computer Supported Collaborative Learning, CSCL; Strijbos et al. 2004). Educators increasingly see new information and communication technologies integrated into CSCL (e.g., multimedia, simulations, external representations, group awareness widgets, and coordination tools) as useful for enhancing cognitive performance (Kirschner et al. 2014; Johnson and Johnson 1999) and stimulating knowledge construction (Stahl 2004). Students in CSCL environments have reported higher levels of learning (Hertz-Lazarowitz and Bar-Natan 2002) and have been shown to make higher quality decisions, to deliver completer reports, to participate more equally in the learning process (Fjermestad 2004; Janssen et al. 2007), and to engage in more complex and challenging discussions Järvelä et al. (2008) than when working alone. They also have reported higher levels of satisfaction compared to students in contiguous groups (Fjermestad 2004).

Recent theories of collaborative learning explain the process of sharing in collaboration and stress the importance of meta-communicative awareness and successful strategy coordination, aspects of socially shared regulation of learning (SSRL), that are emerging in collaborative learning research (e.g. Barron 2003; Dillenbourg 1999). The most widely used definition of collaboration describes it as a construction of shared understanding through interaction with others, where the participants are committed to or engaged in shared goals and problem solving (Roschelle and Teasley 1995).

There are, however, also less positive findings about CSCL and collaboration. Students in CSCL environments sometimes perceive discussions as being more confusing (Thompson and Coovert 2003), less productive (Straus 1997; Straus and McGrath 1994) and more time-consuming (Fjermestad 2004) than in face-to-face settings. They also have been found to experience lower participation (Lipponen et al. 2003), more conflict (Hobman et al. 2002), less group cohesiveness (Straus andMcGrath 1994), and less satisfaction (Baltes et al. 2002) in CSCL environments. This discrepancy can be ascribed to the design of the CSCL environment and/or the social and cognitive behavior of the group members (Kreijns et al. 2003).

Looking at the major problems encountered when using CSCL as pedagogy, one can conclude that many of them might be solved if we had tools at our disposal that could help the participants in CSCL groups in the regulation of their working and learning within the group. Being able to strategically regulate one's own learning and that of others is a vital and increasingly important 21 st century skill. This includes, for example, learners' ability to purposefully influence and adjust their own cognitive, motivational, and emotional behavior as well as that of others for optimal learning and working (Zimmerman and Schunk 2011). Unfortunately, research consistently shows that learners fail to plan adequately, use adaptive learning strategies, and/or leverage technologies for learning, collaborating, and problem solving (Järvelä and Hadwin 2013; Zimmerman and Schunk 2011; Kirschner and van Merrinboer 2013). This happens because the regulation of one's own learning is not easy and needs to be both learned and also often supported with selfregulation tools and/or environments (e.g. Hadwin et al. 2010). Most learners are not equipped to regulate and direct their own learning or might lack the motivation to do so. Additionally, if self-regulation of learning is difficult at the individual level, it becomes even more difficult when interacting with peers and in teams, known as co-regulation and 
shared regulation. In sum, properly planning and strategically adapting one's learning to challenges during the learning process requires being able to strategically regulate oneself (i.e., self-regulated learning; SRL), others (i.e., co-regulated learning; CoRL), and the individuals in a group together (i.e., SSRL) (Hadwin et al. 2011; Winne et al. 2013).

This theoretical paper attempts to explain why socially shared regulation support is needed in CSCL and introduces design principles for supporting SSRL. It extends the idea posited by Järvelä and Hadwin (2013) that successful collaboration in CSCL contexts requires targeted support for promoting individual self-regulatory skills and strategies, peer support, and the facilitation of self-regulatory competence within the group along with shared regulation of learning.

\section{Potentials of and challenges to collaboration}

Decades of research have shown that social interactions are key to successful collaborative learning. According to Dillenbourg (1999), learners benefit from collaboration because they produce interactions such as argumentation (Baker 1994), knowledge building (Bereiter and Scardamalia 2003), mutual regulation (Blaye and Light 1990), or positive conflict resolution (Doise and Mugny 1984). The extent to which these collaborations between group members lead to elaboration of new knowledge depends on the quality of these interactions, especially the process of building and maintaining shared understanding (Kirschner et al. 2008; Roschelle and Teasley 1995). Also, social, non-task related affective interactions, such as feelings of group cohesiveness, team orientation, mutual trust, and sense of community (Fransen et al. 2013; Fransen et al. 2011; Kreijns and Kirschner 2004), are keys to successful collaboration.

Evidence for motivational benefits and challenges of collaborative groups has been recently discussed (Kempler Rogat et al. 2013). Researchers have identified motivating features of group work, such as the integration of challenging tasks for supporting interest (Järvelä and Renniger 2014) or individual accountability and interdependence (Cohen 1994). Others have studied motivational challenges within collaborative learning related to different goals, priorities, and expectations within the group toward group activities (Järvelä et al. 2010). Even though there is an increasing interest in motivation in collaborative learning groups, (Belland et al. 2013) remind us that when designing learning environments, in general, motivation has been ignored in the designs of learning environments.

While the above-mentioned aspects can all be considered success factors, there are also a number of challenges or failure factors that can negatively influence collaboration. Many things can go wrong in collaboration, and cognitive, motivational, and socioemotional challenges may emerge (Van den Bossche et al. 2006), even when the group activity is carefully pedagogically designed (Kirschner et al. 2006). Cognitive challenges may derive from difficulties in understanding others' thinking or negotiating of multiple perspectives

Table 1 Target of regulation in collaborative learning task

\begin{tabular}{lll}
\hline & Regulation target \\
\hline Factors & Cognitive & Task, content, understanding, strategies, behavior \\
& Motivational & Goals, interest, beliefs, expectations \\
& Emotional & Social interaction, trust, sense of community \\
\hline
\end{tabular}


(Kirschner et al. 2008; Mäkitalo et al. 2002). Motivational problems, in turn, can emerge due to differences in group members' goals, priorities, and expectations (Blumenfeld et al. 1996; Järvelä et al. 2008). In sum, earlier research recognized a need for supporting the challenging factors of collaboration in their cognitive, motivational, and emotional regulation targets of group processes (see Table 1.).

\section{Socially shared regulation of learning in collaborative groups}

There is a strong consensus that successful learners self-regulate their learning; that is, they use a repertoire of cognitive, behavioral, and motivational strategies to guide and enhance their learning processes while completing academic tasks (Schunk and Zimmerman 2008). Since group learning activities bring together multiple self-regulating agents (Volet et al. 2009), the study of interpersonal regulation has been focused on the articulation of individual and social processes (Järvelä et al. 2010). The mainstream of the research on self-regulation has dealt with individual learning situations, but the notion that social context is important in students' self-regulated learning is evidenced in a wide range of SRL research, and research into social aspects of SRL has increased considerably in recent years (Hadwin et al. 2011). Co-regulation (CoRL) builds on Vygotskian and neo-Vygotskian theories that suggest that social interactions with individuals who are more capable facilitate students' development of SRL through internalizing the modeled cognitive processes. CoRL emphasizes the importance of giving and receiving support in peer interactions (McCaslin 2009).

In collaborative learning research, regulatory processes have been usually considered from a cognitive perspective and, thus, the definition has been linked to cognitive processes involved in or instrumental for knowledge co-construction (Hmelo-Silver and Barrows 2008), socio-cognitive dynamics of knowledge building (Zhang et al. 2007), knowledge convergence (Weinberger et al. 2007), or task- and team-related aspects (Fransen et al. 2013). What is important and different in the shared regulation of learning is that self-regulated learning theory extends conceptions of learning beyond cognitive processes and outcomes, acknowledging the interactive roles of motivation, emotion, metacognition, and strategic behavior in successful learning (Zimmerman and Schunk 2011). SSRL refers to processes by which group members regulate their collective activity. This type of regulation involves interdependent or collectively shared regulatory processes, beliefs, and knowledge (e.g., strategies, monitoring, evaluation, goal setting, motivation, and metacognitive decision making) orchestrated in the service of a coconstructed or shared outcome (Hadwin et al. 2011).

Thus far, research has emphasized the development and testing of the functionality and usability of technology-based tools for the cognitive aspects of learning and collaborating (e.g., scripting: Fischer et al. 2013), paying little attention to researching how emerging technologies can be leveraged to support learners and collaborators to effectively plan, monitor, and adapt their own, their peers', and collective engagement (Järvelä and Hadwin 2013; Kirschner and Erkens 2013). This is to say, the metacognitive, social, motivational, and emotional aspects related to being/becoming aware of how one learns alone and with others have been neglected.

\section{Traditions for supporting social and cognitive performance in CSCL}

Many efforts have been made to support students' social and cognitive performance in CSCL. Much of the research that has been carried out with respect to CSCL, as well as the 
tools that have been developed to facilitate CSCL, has concentrated on the educational and/ or the technological affordances that can be stimulated, sometimes to the detriment of social affordances. Here, a few definitions need to be given.

Gibson (1977) proposed the term affordance to refer to the relationship between an object's physical properties (its artifacts) and the characteristics of an agent (the user) that enables particular interactions between an agent and an object. Gibson explained that "the affordance of anything is a specific combination of the properties of its substance and its surfaces with reference to an animal" (p. 67). Norman (1990) and Gaver (1996) appropriated the term as a conceptual tool for discussing the design of interactive systems and, respectively, to speak of perceived and perceptible affordances. These perceived affordances are limited by physical (you cannot see through opaque glass), logical (you do not put a window at the bottom of a door), and cultural (you do not put a window in a toilet door) constraints, and cultural conventions (you do not walk into someone's room and interrupt a conversation if you see that the conversation is taking place through the window in the door).

Technological affordances are those properties of an object or medium that affect how they can be/are used, as well as how and if they are perceived and the relationships that exist between the properties and the use/user. Kirschner (2002) argued, for example, that what we see on a computer screen (e.g., a button or a blue hyperlink node) is not an affordance, but rather the visual feedback advertising the affordance (i.e., a place where you can go to with a mouse or touch-pad and right-click or left-click to initiate some further action) - the perceived affordance. When affordances are perceived, a link between a perception (i.e., here is a button or a hyperlink) and an action (i.e., using the right or left mouse button to initiate the action attributed to the button or hyperlink) can result: the perception-action coupling.

Educational affordances are those characteristics of an artifact (e.g., how a chosen educational paradigm is implemented) that determine if and how a particular learning behavior could possibly be enacted within a given context (e.g., a project team or distributed learning community). Educational affordances can be defined as the relationships between the properties of an educational intervention and the characteristics of the learner (for CSCL: a learner and learning group) that enable particular kinds of learning by the individual (for CSCL: members of the group too).

Bradner et al. (1999) define social affordance as "the relationship between the properties of an object and the social characteristics of a group that enable particular kinds of interaction among members of that group" (p. 153). Dieberger (2000) considers awareness of other people's activities to be an essential ingredient for collaborative work. An overheard conversation and the awareness of what other people are working on can trigger chance conversations in hallways or informal talk that often prove more important for a project then the meeting itself. Mulder et al. (2002) confirm the value of such social, non task-related activity, noting a marked increase in task/domain related work following sessions in which there was a high degree of social activity between group members.

In the "physical" world of education, all three types of affordances abound for teaching and learning, including casual and inadvertent interactions. In the "virtual" world, instructional designers and developers have stressed technological and educational affordances and have developed many tools for their perception and use, but tools dedicated to social affordances as well as thinking about their necessity are still rudimentary.

Kreijns et al. (2013) introduce a theoretical framework for CSCL consisting of three core elements: sociability, social space, and social presence, along with their relationships with group members' mental models, social affordances, and learning outcomes. It 
postulates that the three core elements influence the social interaction needed for learning and the emergence of a social space to facilitate learning in teams. This has found its operationalization in two tools (Kirschner et al. accepted), namely a peer feedback tool and a reflection tool. These tools make group members aware of their individual behavior and that of the group and then allow/coerce them into reflecting and then acting upon this awareness. It is assumed that this awareness is necessary for group members to set goals and formulate plans for improving social and cognitive group performance-in other words, the augmentation of the CSCL environment with tools or widgets that influence social interaction (Kirschner et al. 2004) with the goal of positively affecting social and cognitive performance in a CSCL environment.

Currently, there is an emerging interest in developing technological tools for supporting, prompting and scaffolding SRL (Järvelä and Hadwin, 2013). Contemporary research in computer-supported collaborative learning contexts follows mostly three research traditions, namely a) regulation in the context of computer based pedagogical tools (Winters and Azevedo, 2005), (b) supports for group awareness (Janssen et al. 2011), and most recently, (c) supporting shared regulation in CSCL (Winne et al. 2010). These traditions share the common goal of attempting to support or guide student engagement in individual and/or collaborative learning and are aimed at regulating learning within the domain being learned.

One line of research has been developing computer based pedagogical tools to support self-regulated learning (Azevedo and Hadwin 2005; Azevedo et al. 2010; Perry and Winne 2006; Puntambekar and Hübscher 2005). The idea behind computer-based pedagogical tools is that learners possess self-regulated learning skills but do not necessary activate those skills when needed. Pedagogical tools can vary from being relatively short-time reminders (e.g. pop-up windows that prompt the user) to goal-setting and planning tools that depend on the learning phase (Bannert and Reimann 2012). In addition, these tools can be relatively stable, and they are available throughout learning; learners can choose when and how to use the tools provided (Perry and Winne 2006). However, the problem is that not all learners need the same type of support, and it is not clear how to tailor optimal support for each of them.

To solve this problem, pedagogical agents and adaptive system elements are recent innovations advancing the original notion of computer-based pedagogical tools. The idea is that these adaptive system elements have the potential to react "on the fly" to learner activity and provide tailored targeted support for SRL (Azevedo et al. 2010). The purpose of these agents is to enhance metacognitive awareness and support the environment's ability to model and facilitate SRL. The problem is that it is difficult to determine what exactly signals the need for self-regulated learning, especially when taking into account varying task types, situations, and characteristics of a learner. Typically the support provided by computer based pedagogical tools is focused on cognitive and metacognitive aspects of self-regulated learning (Devolder et al. 2012). There has been a vast amount of empirical and theoretical research indicating how learners engage to SRL and methods to promote such behavior (Azevedo and Hadwin 2005). Still, there is not much research on how to implement pedagogical tools for motivation regulation or SSRL and how to provide adaptive support for each learner (Devolder et al. 2012; Järvelä and Hadwin 2013; Järvelä et al. 2012).

Another line of research has worked for supporting group awareness and sociability (Kreijns et al. 2013). Kreijns et al. combine two perspectives, namely a (1) technological system perspective (advanced by Kreijns et al. 2002) developed in the area of CSCL environments together with social presence and social space and (2) social system 
perspective (advanced by Preece 2000) developed in the area of online communities along with usability issues like ease-of-use, learnability, chance of making errors, and so on (for an in-depth discussion see Kreijns $2004^{1}$ ). Both perspectives must be combined to provide insights into how to increase social interaction in the cognitive dimension as well as in the socioemotional dimension. In their opinion, a sound social space is the key to allowing group members using CSCL to gain a feeling of relatedness, group cohesiveness, trust, and respect for each other. This then can 'afford' the SSRL.

An extension of this has been carried out by Kirschner et al. accepted which is the culmination of research done together and separately by all four authors, Their combined research has studied the effects of a peer feedback tool and a reflection tool on (1) perceived social and cognitive behavior, and (2) social and cognitive group performance. Results (Kirschner et al. accepted; Phielix et al. 2010; Phielix et al. 2011) showed that groups using these tools exhibit better social and cognitive behavior, show more convergence between their assessments of themselves as well as their peers, and higher social group performance, than groups not using tools (for an in-depth discussion see Phielix $2012^{2}$ ). In other words, it is possible to use these tools to lay the foundation of good team work and the regulation of team learning activities.

Järvelä and her colleagues' approach have been to develop supports for acquisition of the regulation skills themselves and activation of regulatory processes during collaborative learning. Earlier efforts in the field were aimed primarily at individual support, and not at sharing regulation among group members. Our research has focused on promoting and sustaining socially shared regulatory processes beyond the introduction of collaborative software tools (Järvelä et al. 2013; Miller et al. 2014).

\section{Designing support for socially shared regulation of learning (SSRL)}

Recent decades of research has shown that while trying to understand social and collaborative learning, we have to consider an extremely complex set of variables: cognitive, social, emotional, motivational, and contextual variables interacting with each other in a systemic and dynamic manner (Thompson and Fine 1999). Hadwin et al. (2011) claim that regulated learning is the quintessential skill in collaborative learning. Working together means co-constructing shared task representations, shared goals, and shared strategies. It also means regulating learning through shared metacognitive monitoring and control of motivation, cognition, and behavior.

The idea proposed here is to design supports that enable learners to increase awareness of their own learning processes and that of others to effectively and efficiently learn alone and in groups. We emphasize three design principles for supporting SSRL: (1) increasing learners' awareness of their own and others' learning process, (2) supporting the externalization of students' and others' learning process in a social plane and helping in sharing and interaction, and (3) prompting the acquisition and activation of regulatory processes (See Table 2). These three principles, which are next introduced, are grounded on our own and other colleagues of theoretical and empirical work on social interaction on learning.

\footnotetext{
${ }_{1}$ http://dspace.learningnetworks.org/bitstream/1820/1030/1/Dissertation\%20Kreijns\%202004.pdf.

${ }^{2}$ http://dspace.library.uu.nl/bitstream/handle/1874/255570/phielix.pdf?sequence=2.
} 


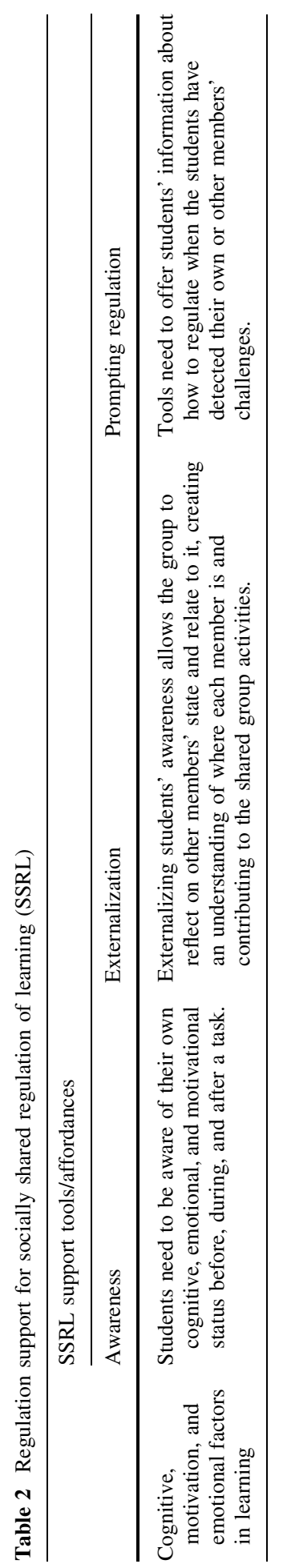


Awareness

Awareness is the knowledge or perception of a situation or fact. In CSCL, there are a number of types of awareness that are important. According to Bodemer and Dehler (2011), behavioral awareness refers to information about a group member's activities in the CSCL environment, cognitive awareness refers to information about the knowledge of the group members, and social awareness refers to information about the functioning of the group as perceived by its members. Furthermore, the awareness information for the three types of group awareness "can be provided on individual learners, on the group as a whole, or on both" (p. 1043). Fransen et al. (2013) make a further distinction, namely a taskrelated awareness when referring to behavioral and cognitive awareness and to teamrelated awareness when referring to social awareness within a team.

Social space and sharing in interaction

The key aspect is that a shared space is needed in which members can collaborate to promote SSRL in the groups, where they can be creative and decide how to regulate their efforts and actions. Shared space does not only mean a joint "physical" (face-to-face communication) or "virtual" (e.g., chat) environment, but it is also to encourage sociability and socioemotional interaction. Social space is defined as the network of interpersonal and social relationships among group members embedded in the group norms and values, rules and roles, beliefs, and ideas (Kreijns et al. 2013). In a practical sense, this implies creating tools that target the phases of regulated learning such that students are able and stimulated to plan together, monitor how the group is performing, evaluate the final product against the standards set up at the beginning, and finally regulate/change accordingly to achieve their learning goals.

\section{Prompting regulation}

Research in the individual self-regulation field has found that interventions should aim to promote planning, monitoring, and evaluating and that the most successful interventions are composed of an array of aspects: cognitive, motivational, and emotional (e.g. Dignath and Büttner 2008). Based on our own work on successful learning (Kirschner et al. 2011), we aim to use technological tools to successfully support specific phases of regulated learning, such as task understanding (Fransen et al. 2011), planning, strategic action, and motivation regulation (Järvelä and Hadwin 2013; Winne and Hadwin 1998). Our recent research has, for example, used computer-generated log-file traces to identify and understand learning in student groups (Malmberg et al. 2010), identifying challenging learning situations and typical learning patterns in those groups along with temporal characteristics on evolving learner actions during learning (Malmberg et al. 2014).

Important aspects of socially shared regulation include: (a) metacognitive, metamotivational, and meta-emotional knowledge is constructed about the collaborative learning processes, such as negotiating and aligning representations of task requirements and goals; (b) educators need to share in the process of monitoring and evaluating progress and to construct strategies that might help a group to work more effectively and efficiently together; and (c) it is essential that regulated learning focuses on learning and collaboration processes, rather than processes and outcomes associated with domain task completion. 


\section{Illustrative example of supporting ssrl in collaborative group work}

Based on the three design principles for supporting SSRL presented; awareness, externalization and prompting regulation, we tailored an existing online tool that promoted collaborative work to enhance SSRL. The Virtual Collaborative Research Institute $\left(\mathrm{VCRI}^{3}\right)$ has been used previously to enhance collaborative work, helping the students selfassess and peer-assess with higher accuracy and with making their judgments explicit. This resulted in better collaborative work (Phielix et al. 2011). Within the VCRI, we used already existing features (Radar and Chat) and reformulated another (Co-writer) to create two new ones (OurPlanner and OurEvaluator).

Radar is a diagram with six different axes, with a 100-point Likert scale organized around five positions. Radar enhances awareness of group members' social and cognitive behavior, and in turn, supports social and cognitive group performance, providing users with anonymous information on how their cognitive and social behaviors are perceived by themselves, their peers, and the group (Phielix 2012).

\section{Awareness of SRL and SSRL}

The Radar tool (see Fig. 1) was tailored to promote awareness of individual SRL and SSRL. First, group members reported aspects of their own self-regulation at the individual level (e.g., I know how to perform the task) and one aspect related to the group work (e.g., I think the group is capable of performing the task). In Radar, each of the axes represents different questions: I know how to perform the task/I understand the task/This task is interesting/My feelings influence on my working/I feel capable of doing this task, and I think the group is capable of performing the task. The students filled out the Radar individually, directly after receiving the task instructions. Second, Radar was used to promote SSRL. When all the group members have filled out their Radar, they can see each others' Radars on the screen. This is to say that the group's members are able to be aware not only of their cognitive, motivational, and emotional aspects before they start the task, but also where the group stands as a whole. This enables a group to become aware of possible challenges that might hinder their collaboration and to activate appropriate strategies. Radar was used to increase individuals' and groups' awareness of their SRL and SSRL in a learning situation.

Socially shared planning

After completing the Radar, the group members filled in as a group OurPlanner, which prompted groups to identify and develop SSRL strategies. This tool consists of six different questions that scaffold the group planning before starting to perform the activity. These questions are: (1) Describe your current task, (2) What is the purpose of this task?, (3) What is your goal for this task?, (4) Describe what you need to do to achieve that goal, (5) What is your main challenge as a group?, (6) What are you going to do as a group to overcome this challenge? In sum, OurPlanner promotes aspects of SSRL such as task understanding, planning, goal setting, and strategy use.

\footnotetext{
3 http://edugate.fss.uu.nl/ crocicl/vcri_eng.html.
} 


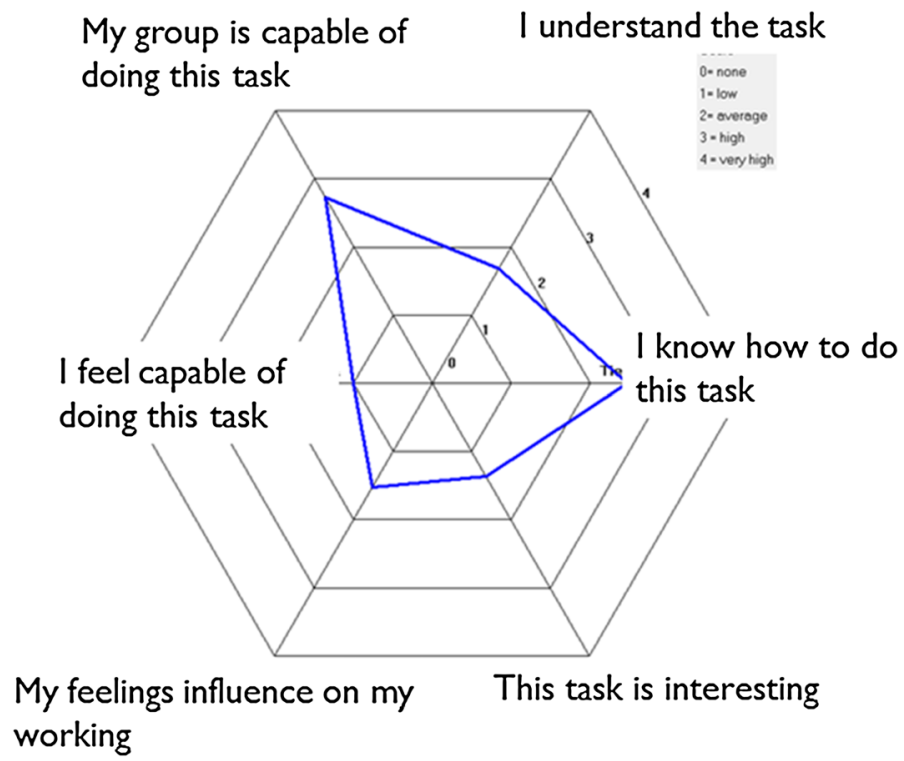

Fig. 1 Radar + SSRL support

Socially shared evaluation

After completing the learning task, the group filled in OurEvaluator, which is a similar tool to OurPlanner, but the focus is on evaluating what the group has been doing. It is composed of seven questions: (1) How did your work match the task purposes? (2) Did you achieve your goal as a group? If so, how? If not, why? (3) How did your group work to achieve that goal? (4) How did your plan work in action? (5) What was your main challenge? (6) What did you do as a group to overcome this challenge? and (7) Why are you satisfied with your group work? OurEvaluator provides an opportunity for the group to evaluate their joint efforts and to reflect on which aspects of their regulation might need to be changed for future performance.

Implementing radar, OurPlanner, and OurEvaluator

Radar, OurPlanner, and OurEvaluator were used in the research project called "Prospects," where the participants were first-year teacher education students. The aim of Prospects is to promote future teachers self-regulation and socially shared regulation skills. In the current study, the teacher education students $(N=103)$ participated in a "multi-media as a learning project" and worked on a collaborative task to create a digital story. The course was divided into nine sessions in which students worked collaboratively (three to four member per group). Each session was divided in two different parts: (1) a face-to-face part at the university computer class with teacher support and then (2) an online part in which students worked from their own computers.

The working procedure was as follows (see Fig. 2). First, in the face-to-face phase, the task was introduced by the instructor. Then the students individually completed the Radar and filled out OurPlanner questions in one computer as a group, and their face-to-face 


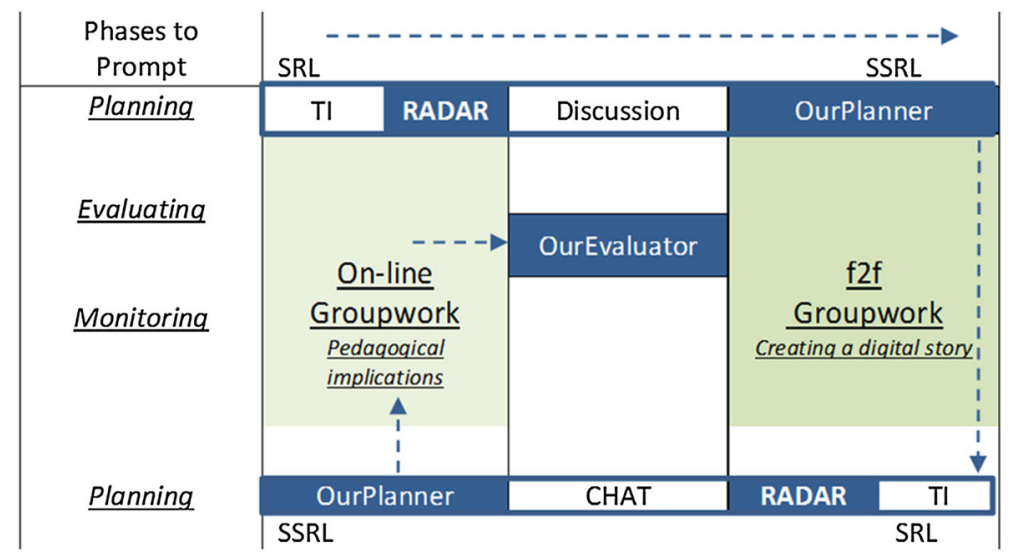

Fig. 2 Prospects design (including Radar + SSRL, OurPlanner, and OurEvaluator)

conversations were audio-recorded. During the online group work, the procedure was the same. However, the students were working online synchronously, using a chat tool while discussing OurPlanner questions. After the online task assignment, the students filled in OurEvaluator as a group.

Considering design principles presented in this paper for promoting socially shared regulated learning, it is now discussed how they were considered in the Prospects design. The first principle was to increase learners' awareness of their own and others' learning process. This was done by using Radar and its visualization. At the individual level, the group members had to first think about their own SRL in a learning situation. Group level awareness was increased with a visualization of how the other members were thinking (cognitive) and feeling (motivation and emotions) about the current learning situation. The second and third principles were supporting externalization of students' own and others' learning process in a social plane and helping in sharing and interaction and prompting the acquisition and activation of regulatory processes. These two principles are promoted via OurPlanner and OurEvaluator, as both tools make explicit the group strategies and shared task goals. By externalization strategies and goals, the different group members can elaborate and activate the joint strategies by interacting with their peers.

\section{Conclusions and implications for the SSRL support design}

Our aim is to progress a pedagogical and technological design to support and promote SSRL. In this paper, we identified three design principles: (1) increasing learners' awareness of their own and others' learning process, (2) supporting the externalization of students' and others' learning process and helping in sharing and interaction, and (3) prompting the acquisition and activation of regulatory processes. We implemented these principles in our current study with the tool set: Radar + SSRL support, OurPlanner, and OurEvaluator. Until now, our data have shown that the SSRL tool supports not only socially shared regulation but also collaborative learning. In our study (Malmberg et al. 2014) identified two different types of groups. The first type confronts mostly environmental and motivational challenges during their collaboration, and they do not develop strategies to overcome those challenges. The second type develops more advanced 
regulatory strategies over time. The findings show that group members develop more advanced regulatory strategies because they recognize a need (with the help of SSRL tool) for coordinating and maintaining a positive socioemotional balance in their group work.

According to the recent discussions on social aspects of SRL, collaboration not only requires self-regulation but also allows each team member to support fellow team members in successfully regulating their learning and helping the team to come together to collectively regulate learning (Järvelä and Hadwin 2013; Winne et al. 2013). We conclude that SSRL support should increase metacognitive awareness and provide regulation support for collaboration at all levels: individual and group. Activating the students' cognitive, motivational, and emotional, predispositions for the task will provide them with the information needed for a more successful collaboration and performance.

This approach may also have a second beneficial effect, namely the scaffolding of second-order SSRL skills (van Merriënboer and Kirschner 2013). In their book "Ten Steps to Complex Learning," they argue that there are two types of scaffolds for learning in educational settings, namely first-order and second-order scaffolds. First-order (i.e., regular) scaffolding provides support and guidance for acquiring and performing in a specific domain-here, for using SSRL to learn in the specific learning situation/course in question. Second-order scaffolding provides support and guidance for acquiring and performing in a self-directed way. Here, that would mean applying SSRL in all situations (i.e., near and far transfer of SSRL skills to other collaborative learning, working, and even social situations).

One of the future challenges in (socially shared) regulation support tool development is tailoring it to the individual and collective learning challenges. Until now, our research on the cognitive, motivational, emotional, and social aspects of learning (e.g., Malmberg et al. 2014; Malmberg et al. 2010) shows that tracing learners' strategic activity as a continuous process and not only as a series of momentary snapshots can inform the quality of students' strategy use and ultimately their learning. This information can be analyzed and tailored to scaffold individual SRL support and group level regulation. The problem is that the relevant learning traces where the whole process is visible and where it can be seen how specific activities relate to the learning process as a whole are often not salient (Winne et al. 2011) and, thus, cannot be used by learners in their learning. Future efforts are needed to discern learning-relevant information and implement novel ways to increase the saliency of this information so as to facilitate learning. For example, to deal with all of this information and make sense of it for both learner and teacher, learning analytics can be used (Greller and Drachsler 2012). Learning analytics is the data-driven analysis of learning activities and environments involving measurement, collection, analysis, and reporting of data about learners and their contexts to understand and optimize learning and the environments in which it occurs. As such, it can be used to analyze and visualize learning patterns and provide learners and teachers with information to optimize the cognitive, motivational, and emotional components of individual and collaborative learning.

Acknowledgments Research funded by the Finnish Academy, Project no. 259214 (PROSPECTS, PI: Sanna Järvelä).

\section{References}

Azevedo, R., \& Hadwin, A. F. (2005). Scaffolding self-regulated learning and metacognition: Implications for the design of computer-based scaffolds. Instructional Science, 33(5-6), 367-379. doi:10.1007/ s11251-005-1272-9. 
Azevedo, R., Johnson, A., Chauncey, A., \& Burkett, C. (2010). Self-regulated Learning with MetaTutor: Advancing the science of learning with metacognitive tools. In M. S. Khine \& I. M. Saleh (Eds.), New Science of Learning (pp. 225-247). New York: Springer.

Baker, M. J. (1994). A Model for Negotiation in Teaching-Learning Dialogues. Journal of Artificial Intelligence in Education, 5(2), 199-254.

Baltes, B. B., Dickson, M. W., Sherman, M. P., Bauer, C. C., \& LaGanke, J. (2002). Computer-mediated communication and group decision making: A meta-analysis. Organizational Behavior and Human Decision Processes, 87(1), 156-179.

Bannert, M., \& Reimann, P. (2012). Supporting self-regulated hypermedia learning through prompts. Instructional Science, 40(1), 193-211. doi:10.1007/s11251-011-9167-4.

Barron, B. (2003). When smart groups fail. Journal of the Learning Sciences, 12(3), 307-359. doi:10.1207/ s15327809j1s1203_1.

Belland, B. R., Kim, C. M., \& Hannafin, M. J. (2013). A framework for designing scaffolds that improve motivation and cognition. Educational Psychologist, 48(4), 243-270. doi:10.1080/00461520.2013.838920.

Bereiter, C., \& Scardamalia, M. (2003). Learning to work creatively with knowledge. In E. De Corte, L. Verschaffel, N. Entwistle, \& J. van Merriënboer (Eds.), Powerful learning environments: Unraveling basic components and dimensions. (Advances in Learning and Instruction Series) (pp. 55-68). Oxford, UK: Elsevier Science.

Blaye, A., \& Light, P. (1990). Computer-based learning: The social dimensions. In H. C. Foot, M. J. Morgan, \& R. H. Shute (Eds.), Children helping children (pp. 135-150). Chichester: Wiley.

Blumenfeld, P. C., Marx, R. W., Soloway, E., \& Krajcik, J. (1996). Learning with peers: From small group cooperation to collaborative communities. Educational Researcher, 25(8), 37-40.

Bodemer, D., \& Dehler, J. (2011). Group awareness in CSCL environments. Computers in Human Behavior, 27(3), 1043-1045.

Bradner, E., Kellogg, W. A., \& Erickson, T. (1999). The adoption and use of 'BABBLE': A field study of chat in the workplace. In S. Bødker, M. Kyng, \& K. Schmidt (Eds.), ECSCW'99 (pp. 139-158). Netherlands: Springer.

Cohen, E. G. (1994). Restructuring the classroom: Conditions for productive small groups. Review of Educational Research, 64(1), 1-35. doi:10.3102/00346543064001001.

Devolder, A., Van Braak, J., \& Tondeur, J. (2012). Supporting self-regulated learning in computer-based learning environments: Systematic review of effects of scaffolding in the domain of science education. Journal of Computer Assisted Learning, 28, 557-573.

Dieberger, A. (2000). Where did all the people go? A collaborative Web space with social navigation information. Poster presented at the 9th International World Wide Web Conference (WWW9), Amsterdam, The Netherlands. Accessed from the World Wide Web on June 8, 2002 at http://juggle5. 50megs.com/WORK/publications/SwikiWriteup.html.

Dignath, C., \& Büttner, G. (2008). Components of fostering self-regulated learning among students. A metaanalysis on intervention studies at primary and secondary school level. Metacognition and Learning, 3, 231-264. doi:10.1007/s11409-008-9029.

Dillenbourg, P. (1999). What do you mean by 'collaborative learning'? In P. Dillenbourg (Ed.), Collaborative-learning: Cognitive and computational approaches (pp. 1-19). Oxford: Elsevier.

Doise, W., \& Mugny, G. (1984). The social development of intellect. Oxford: Pergamon Press.

Fischer, F., Kollar, I., Stegmann, K., \& Wecker, C. (2013). Toward a script theory of guidance in computer-supported collaborative learning. Educational Psychologist, 48(1), 56-66. doi:10.1080/00461520.2012.748005.

Fjermestad, J. (2004). An analysis of communication mode in group support systems research. Decision Support Systems, 37, 239-263.

Fransen, J., Kirschner, P. A., \& Erkens, G. (2011). Mediating team effectiveness in the context of collaborative learning: The importance of team and task awareness. Computers in Human Behavior, 27(3), 1103-1113. doi:10.1016/j.chb.2010.05.017.

Fransen, J., Weinberger, A., \& Kirschner, P. (2013). Team effectiveness and team development in CSCL. Educational Psychologist, 48, 9-24. doi:10.1080/00461520.2012.747947.

Gaver, W. W. (1996). Situating action II: Affordances for interaction: The social is material for design. Ecological Psychology, 8(2), 111-129. doi:10.1207/s15326969eco0802_2.

Gibson, J. J. (1977). The Theory of Affordances. In R. Shaw \& J. Bransford (Eds.), Perceiving, Acting, and Knowing: Toward an Ecological Psychology (pp. 67-82). Hillsdale, NJ: Lawrence Erlbaum.

Greller, W., \& Drachsler, H. (2012). Translating learning into numbers: A generic framework for learning analytics. Journal of Educational Technology \& Society, 15(3), 42-57.

Hadwin, A. F., Järvelä, S., \& Miller, M. (2011). Self-regulated, co-regulated, and socially shared regulation of learning. In B. J. Zimmerman \& D. H. Schunk (Eds.), Handbook of self-regulation of learning and performance (pp. 65-84). New York: Routledge. 
Hadwin, A. F., Oshige, M., Gress, C. L. Z., \& Winne, P. H. (2010). Innovative ways for using gStudy to orchestrate and research social aspects of self-regulated learning. Computers in Human Behavior, 26, 794-805.

Hertz-Lazarowitz, R., \& Bar-Natan, I. (2002). Writing development of Arab and Jewish students using cooperative learning (CL) and computer-mediated communication (CMC). Computers \& Education, 39(1), 19-36.

Hmelo-Silver, C. E., \& Barrows, H. S. (2008). Facilitating collaborative knowledge building. Cognition and Instruction, 26(1), 48-94. doi:10.1080/07370000701798495.

Hobman, E. V., Bordia, P., Irmer, B., \& Chang, A. (2002). The expression of conflict in computer-mediated and face-to-face groups. Small Group Research, 33, 439-465.

Janssen, J., Erkens, G., Kanselaar, G., \& Jaspers, J. (2007). Visualization of participation: Does it contribute to successful computer-supported collaborative learning. Computers \& Education, 49, 1037-1065.

Janssen, J., Erkens, G., \& Kirschner, P. A. (2011). Group awareness tools: It's what you do with it that matters. Computers in Human Behavior, 27(3), 1046-1058. doi:10.1016/j.chb.2010.06.002.

Järvelä, S., \& Hadwin, A. F. (2013). New frontiers: Regulating learning in CSCL. Educational Psychologist, 48(1), 25-39. doi:10.1080/00461520.2012.74800.

Järvelä, S., Järvenoja, H., \& Malmberg, J. (2012). How elementary school students' regulation of motivation is connected to self-regulation. Educational Research and Evaluation, 18(1), 65-84.

Järvelä, S., Järvenoja, H., Malmberg, J., \& Hadwin, A. (2013). Exploring socially-shared regulation in the context of collaboration. The Journal of Cognitive Education and Psychology, 12(3), 267-286. doi:10. 1891/1945-8959.12.3.267.

Järvelä, S., Järvenoja, H., \& Veermans, M. (2008a). Understanding dynamics of motivation in socially shared learning. International Journal of Educational Research, 47(1), 122-135.

Järvelä, S. \& Renniger, K. R. (2014, in press). Designing for learning: Engagement, interest, and motivation. Sawyer, K. (Ed.). Cambridge Handbook of the Learning Sciences.

Järvelä, S., Veermans, M., \& Leinonen, P. (2008b). Investigating students' engagement in a computersupported inquiry - a process-oriented analysis. Social Psychology in Education, 11, 299-322.

Järvelä, S., Volet, S., \& Järvenoja, H. (2010). Research on Motivation in Collaborative Learning: Moving beyond the cognitive-situative divide and combining individual and social processes. Educational Psychologist, 45(1), 15-27.

Johnson, D. W., \& Johnson, R. T. (1999). Learning together and alone: Cooperative, competitive, and individualistic learning (5th ed.). Boston, MA: Allyn and Bacon.

Kempler Rogat, T. K., Linnenbrink-Garcia, L., \& DiDonato, N. C. (2013). Motivation in collaborative groups. In C. E. Hmelo-Silver, C. A. Chinn, C. Chan, \& A. M. O’Donnell (Eds.), The international handbook of collaborative learning (pp. 250-267). New York: Routledge.

Kirschner, P. A. (2002). Cognitive load theory: Implications of cognitive load theory on the design of learning. Learning and Instruction, 12(1), 1-10. doi:10.1016/S0959-4752(01)00014-7.

Kirschner, P. A., Beers, P. J., Boshuizen, H. P. A., \& Gijselaers, W. H. (2008). Coercing shared knowledge in collaborative learning environments. Computers in Human Behavior, 24(2), 403-420. doi:10.1016/j. chb.2007.01.028.

Kirschner, P. A., \& Erkens, G. (2013). Toward a framework for CSCL research. Educational Psychologist, 48(1), 1-8. doi:10.1080/00461520.2012.750227.

Kirschner, P. A., Kirschner, F., \& Janssen, J. (2014). The collaboration principle in multimedia learning. In R. Mayer (Ed.), The Cambridge handbook of multimedia learning (2nd ed., pp. 547-575). New York: Cambridge University Press.

Kirschner, P. A., Kreijns, K., Phielix, C., \& Fransen, J. Awareness of cognitive and social behaviour in a CSCL environment. Journal of Computer Assisted Learning (accepted).

Kirschner, F., Paas, F., Kirschner, P. A., \& Janssen, J. (2011). Differential effects of problem-solving demands on individual and collaborative learning outcomes. Learning and Instruction, 21(4), 587-599. doi:10.1016/j.learninstruc.2011.01.001.

Kirschner, P., Strijbos, J. W., Kreijns, K., \& Beers, P. J. (2004). Designing electronic collaborative learning environments. Educational Technology Research and Development, 52(3), 47-66. doi:10.1007/ BF02504675.

Kirschner, P. A., Sweller, J., \& Clark, R. E. (2006). Why minimal guidance during instruction does not work: An analysis of the failure of constructivist, discovery, problem-based experiential and inquirybased teaching. Educational Psychologist, 41(2), 75-86.

Kirschner, P. A., \& van Merrinboer, J. J. G. (2013). Do learners really know best? Urban legends in education. Educational Psychologist, 48(3), 169-183. doi:10.1080/00461520.2013.804395.

Kreijns, K. (2004). Sociable CSCL environments: Social affordances, sociability, and social presence. Unpublished $\mathrm{PhD}$ thesis. Open University of the Netherlands, Heerlen, The Netherlands. Available at http://dspace.learningnetworks.org/bitstream/1820/1030/1/Dissertation\%20Kreijns\%202004.pdf. 
Kreijns, K., \& Kirschner, P. A. (2004). Determining sociability, social space and social presence in (a)synchronous collaborating teams. Cyberpsychology and Behavior, 7(2), 155-172.

Kreijns, K., Kirschner, P. A., \& Jochems, W. (2002). Identifying the pitfalls for social interaction in computer-supported collaborative learning environments: A review of the research. Computers in Human Behavior, 19, 335-353.

Kreijns, K., Kirschner, P. A., \& Jochems, W. (2003). Identifying the pitfalls for social interaction in computer-supported collaborative learning environments: a review of the research. Computers in Human Behavior, 19, 335-353.

Kreijns, K., Kirschner, P. A., \& Vermeulen, M. (2013). Social aspects of CSCL environments: A research framework. Educational Psychologist, 48(4), 229-242. doi:10.1080/00461520.2012.750225.

Lipponen, L., Rahikainen, M., Lallimo, J., \& Hakkarainen, K. (2003). Patterns of participation and discourse in elementary students' computer-supported collaborative learning. Learning and Instruction, 13, 487-509.

Mäkitalo, K., Häkkinen, P., Järvelä, S., \& Leinonen, P. (2002). Mechanisms of common ground in casebased web discussions in teacher education. The Internet and Higher Education, 5(3), 247-265.

Malmberg, J., Järvelä, S., Järvenoja, H., \& Panadero, E. (2014, manuscript). Promoting socially shared regulation of learning in CSCL: Patterns of socially shared regulation of learning between high - and low performing student groups.

Malmberg, J., Järvelä, S. \& Kirschner, P. (2014, in press). Elementary school students' strategic activity and quality of strategy use: Does task-type matter? Metacognition and Learning.

Malmberg, J., Järvenoja, H., \& Järvelä, S. (2010). Tracing elementary school students' study tactic use in gStudy by examing a strategic and self-regulated learning. Computers in Human Behavior, 26(5), 1034-1042.

McCaslin, M. (2009). Co-regulation of student motivation and emergent identity. Educational Psychologist, 44(2), 137-146.

Miller, M., Malmberg, J. Hadwin, A., \& Järvelä, S. (2014, submitted). Tracing university studentś construction of shared task perceptions in on-line collaboration.

Mulder, I., Swaak, J., \& Kessels, J. (2002). Assessing group learning and shared understanding in technology mediated interaction. Educational Technology \& Society, 5(1), 35-47.

Norman, D. A. (1990). The design of everyday things. New York: Doubleday.

Perry, N. E., \& Winne, P. H. (2006). Learning from learning kits: gStudy traces of student' self-regulated engagements using software. Psychology of Education Review, 18, 211-228.

Phielix, C. (2012). Enhancing collaboration through assessment \& reflection. Unpublished PhD thesis, Utrecht University, Utrecht, The Netherlands. Available at http://dspace.library.uu.nl/bitstream/handle/ 1874/255570/phielix.pdf?sequence=2.

Phielix, C., Prins, F. J., \& Kirschner, P. A. (2010). Awareness of group performance in a CSCL-environment: Effects of peer feedback and reflection. Computers in Human Behavior, 26, 151-161. doi:10. 1016/j.chb.2009.10.011.

Phielix, C., Prins, F. J., Kirschner, P. A., Erkens, G., \& Jaspers, J. (2011). Group awareness of social and cognitive performance in a CSCL environment: Effects of a peer feedback and reflection tool. Computers in Human Behavior, 27(3), 1087-1102. doi:10.1016/j.chb.2010.06.024.

Preece, J. (2000). Online communities: Designing usability, supporting sociability. Chichester, UK: Wiley.

Puntambekar, S., \& Hübscher, R. (2005). Tools for scaffolding students in a complex environment: What we have gained and what we have missed? Educational Psychologist, 40(1), 1-12.

Roschelle, J., \& Teasley, S. D. (1995). The construction of shared knowledge in collaborative problem solving. In C. O’Malley (Ed.), Computer Supported Collaborative Learning (pp. 69-97). Berlin: Springer.

Schunk, D. H., \& Zimmerman, B. J. (Eds.). (2008). Motivation and selfregulated learning: Theory, research, and applications. New York, NY: Taylor \& Francis.

Stahl, G. (2004). Groupware goes to school: Adapting BSCW to the classroom. International Journal of Computer Applications in Technology, 19(3/4), 1-13.

Straus, S. G. (1997). Technology, group process, and group outcomes: Testing the connections in computermediated and face-to-face groups. Human-Computer Interaction, 12, 227-266.

Straus, S. G., \& McGrath, J. E. (1994). Does the medium matter? The interaction of task type and technology on group performance and member reactions. Journal of Applied Psychology, 79(1), 87-97.

Strijbos, J. W., Kirschner, P. A., \& Martens, R. L. (Eds.). (2004). What we know about CSCL: And implementing it in higher education. Boston, MA: Kluwer Academic.

Thompson, L. F., \& Coovert, M. D. (2003). Teamwork online: the effects of computer conferencing on perceived confusion, satisfaction and post discussion accuracy. Group Dynamics, 7(2), 135-151. 
Thompson, L., \& Fine, G. A. (1999). Socially shared cognition, affect, and behavior: A review and integration. Personality and Social Psychology Review, 3, 278-302.

Van den Bossche, P., Gijselaers, W., Segers, M., \& Kirschner, P. A. (2006). Social and cognitive factors driving teamwork in collaborative learning environments. Small Group Research, 37(5), 490-521.

van Merriënboer, J. J. G., \& Kirschner, P. A. (2013). Ten steps to complex learning (2nd ed.). New York: Taylor \& Francis.

Volet, S. E., Vauras, M., \& Salonen, P. (2009). Self- and social regulation in learning contexts: An integrative perspective. Educational Psychologist, 44(4), 215-226.

Weinberger, A., Stegmann, K., \& Fischer, F. (2007). Knowledge convergence in collaborative learning: Concepts and assessment. Learning and Instruction, 17(4), 416-426.

Winne, P. H., \& Hadwin, A. F. (1998). Studying as self-regulated engagement in learning. In D. Hacker, J. Dunlosky, \& A. Graesser (Eds.), Metacognition in educational theory and practice (pp. 277-304). Hillsdale, NJ: Er.

Winne, P. H., Hadwin, A. F., \& Gress, C. L. Z. (2010). The learning kit project: Software tools for supporting and researching regulation of collaborative learning. Computers in Human Behavior, 26, 787-793.

Winne, P. H., Hadwin, A. F., \& Perry, N. E. (2013). Metacognition and computer-supported collaborative learning. In C. Hmelo-Silver, A. O’Donnell, C. Chan, \& C. Chinn (Eds.), International handbook of collaborative learning (pp. 462-479). New York: Taylor \& Francis.

Winne, P. H., Zhou, R., \& Egan, R. (2011). Designing assessments of self-regulated learning. In G. Schraw \& D. R. Robinson (Eds.), Assessment of higher order thinking skills (pp. 89-120). Charlotte, NC: IAPInformation Age Publishing.

Winters, F. I., \& Azevedo, R. (2005). High school students' regulation of learning during computer-based science inquiry. Journal of Educational Computing Research, 33(2), 189-215.

Zhang, J., Scardamalia, M., Lamon, M., Messina, R., \& Reeve, R. (2007). Socio-cognitive dynamics of knowledge building in the work of nine- and ten-year-olds. Educational Technology Research and Development, 55(2), 117-145. doi:10.1007/s11423-006-9019-0.

Zimmerman, B. J., \& Schunk, D. H. (2011). Motivational sources and outcomes of self-regulated learning and performance. In B. Zimmerman \& D. Schunk (Eds.), Handbook of self-regulation of learning and performance (pp. 49-64). New York, NY: Routledge.

Sanna Järvelä is a full professor of Learning and Educational Technology and a head of the Learning and Educational Technology Research Unit (LET) (http://www.let.oulu.fi/) in the Department of Educational Sciences, University of Oulu, Finland. Her main research interest deal with learning processes in technology enhanced learning social and motivational processes in learning, self-regulated and computer supported collaborative learning.

Paul A. Kirschner is full professor of Educational Psychology at the Welten Institute, Research Centre for Learning, Teaching and Technology on the Open University of the Netherlands and visiting professor at Oulu University. He has a background in teaching, educational psychology and educational technologies for learning. His research focuses on personalized learning, social aspects of learning environments, and the use of new technologies for learning.

Ernesto Panadero received his Ph.D. degree in educational psychology from the Universidad Autónoma de Madrid (Spain). He is currently working at the Department of Educational Sciences and Teacher Education within the Learning and Educational Technology Research Unit (LET), at the University of Oulu (Finland). His research covers aspect related to self-regulated learning and formative assessment.

Jonna Malmberg is a Post Doc researcher at the Learning and Educational Technology Research Unit (LET), University of Oulu. She is interested in self-regulated learning, cognitive aspects of regulation and how technology tools can support solo and collaborative regulation.

Chris Phielix, PhD is a teacher and researcher at the department of Education at Utrecht University in The Netherlands. His research focuses on social aspects of learning environments, computer supported collaborative learning and the use of new technologies for learning (i.e., a reflection and self- and peerassessment tools). 
Jos Jaspers, PhD is an assistant professor at the department of Education at Utrecht University in The Netherlands. He has a background in psychology and is interested in the application of information technology in education and in research. He designs and implements systems for collaborative learning.

Marika Koivuniemi, Doctoral student is preparing her dissertation at the Learning and Educational Technology Research Unit (LET), University of Oulu. She is interested in self-regulated learning, especially higher education students' challenges in their studying.

Hanna Järvenoja, PhD is a Post Doctoral researcher at the Learning and Educational Technology Research Unit (LET), University of Oulu. Her research interest is in self-regulated learning, especially in emotion and motivation regulation in individual and socially-shared learning situations. 